\title{
Creating adaptive athletes: the athletic skills model for enhancing physical literacy as a foundation for expertise
}

\author{
Geert J.P. Savelsbergh ${ }^{* 1}$ and Rene Wormhoudt ${ }^{2}$ \\ 1 Amsterdam Institute of Sport Science, Faculty of Behavioural and Movement Sciences, Vrije University, Amsterdam, \\ The Netherlands \\ ${ }^{2}$ Royal Dutch Football Association, Zeist, The Netherlands
}

Received 18 July 2018, Accepted 29 January 2019

\begin{abstract}
The purpose of the current paper is to advocate that the athletic skills model (ASM) serves as a suitable framework to structure (developmental) movement programs to enhance physical literacy as a foundation for expertise. Taking the non-linear developmental trajectories into account (including the possibility to follow the linear developmental pathway), the ASM applies three "roads" to reach this goal, that is, the concentric approach, creating challenging environments, and exploiting transfer. Each of these separately or in combination with each other will increase the level of physical literacy, that is creating more functional variation leading to an increasement of possibilities for adaptation of those involved (athletes, PE teachers, and coaches). ASM seeks a life-long physical activity participation and to maintain a balance between performance, fitness and health for the recreational as well for the disable and able (elite) athlete.
\end{abstract}

Key words: physical literacy, talent development, expertise, adaptive, life-long participation

\begin{abstract}
Résumé-Former des sportifs adaptables : le modèle des compétences sportives pour optimiser les compétences motrices. L'objectif de cet article est de présenter en quoi le «modèle des habiletés sportives » ( «athletic skills model », ASM) constitue un cadre adapté pour structurer les programmes d'activités physiques qui ciblent le développement des compétences motrices des individus comme le fondement de l'expertise. En s'appuyant sur les trajectoires non-linéaires du développement (y compris la possibilité de suivre une trajectoire linéaire), l'ASM propose trois pistes pour atteindre ce but : l'approche concentrique, la création d'environnements stimulants et l'exploitation des transferts. L'association de ces pistes ou leur utilisation de manière indépendante augmentera le niveau de compétence motrice en créant des variations plus fonctionnelles qui mèneront à davantage de possibilités d'adaptation de la part des personnes impliquées dans le programme (sportifs, professeurs d'éducation physique ou entraîneurs). L'ASM cherche à ce que les sportifs, occasionnels, en situation de handicap ou de haut-niveau s'impliquent dans une activité physique tout au long de sa vie en maintenant un équilibre entre performance, condition physique et santé.
\end{abstract}

Mots clés : savoir-faire physique, développement des talents, expertise, adaptation, participation tout au long de la vie

\section{Introduction}

In the last decade the term "physical literacy" came into vogue and appears with increasing frequency in the physical education literature (Durden-Myers, Pot, \& Whitehead, 2018; Pot, Whitehead, \& Durden-Myers, 2018; Whitehead, Durden-Myers, \& Pot, 2018). The concept of physical literacy refers to the motivation, confidence, physical competence, knowledge and understanding to value and take responsibility for engagement

\footnotetext{
*Corresponding author: g.j.p.savelsbergh@vu.nl
}

in physical activities for life (Whitehead, 2001, 2010). The physically literate person is one who "pursues a lifetime of healthful physical activity" and meets five standards: namely s/he has learned the skills necessary to participate in a variety of physical activities (1), knows the implications and the benefits of involvement in various types of physical activities (2), participates regularly in physical activity (3), is physically fit (4), and values physical activity and its contributions to a healthful lifestyle (5). Ideally, in order to enhance physical literacy, one should start at a young age by familiarizing and educating children in movement programmes. In addition, 
we consider physical literacy as the suitable foundation for a road to expertise. We recently put forward a developmental model, the athletic skills model (ASM), for optimizing talent development through movement education (Wormhoudt, Savelsbergh, Teunissen, \& Davids, 2018). The aim of the current paper is to advocate how the ASM (which we detail in Sect. 2) can be extended to serve as a suitable framework to structure movement programmes to enhance physical literacy with a view of supporting life-long physical activity participation. Indeed, ASM encompasses wellbeing, health, and talent development of children through adolescence to adulthood, and the quest for seeking to maintain a balance between performance, fitness and health for the recreational, for able and disable athlete as well as for elite athlete.

We are now facing a potential crisis with respect to developing physical literacy in (young) children and adolescents. For various and complex reasons, including insufficient physical education at school and lack of outdoor "in the street" play, many countries have raised in the last 30 years a generation of children with limited basic athletic skills (e.g., basic movement skills), like climbing, running, falling, and running (e.g. Vandorpe et al., 2011; Wormhoudt et al., 2018). It is a fact that today's generation of children are significantly less fit than their peers who lived thirty-five years ago (Vandorpe et al., 2011). It is a prominent issue that children get less and less movement experience (Anderson \& Twist, 2005; Tremblay \& Willms, 2000), are tending towards greater obesity (de Onis, Blossner, \& Borghi, 2010; World Health Organization, 2009), and are at greater risk for developing lifestyle diseases such as cardiovascular disease and diabetes later in life.

In contrast, research shows that children who experience a varied pattern of sports and other "movement activities" tend to attain better academic results at school (Singh, Uijtdewilligen, Twisk, van Mechelen, \& Chinapaw, 2012), and are more socially active (TNO Kwaliteit van Leven, 2008). A longitudinal study in the United States (Olympian Report, 1984-1998, Hill, McConnell, Forster, \& Moore, 2002) concluded, among other things, that Olympic medallists practised on average 3.4 sports per person at school and 3.1 sports outside school. This could mean that there is a relation between practising several (multiple) sports and reaching the top in the target sport.

In the last two decades, a wealth of motor learning research has been conducted but not integrated into talent development models with an aim to increase the physical literacy of people (Chapter 4 in Wormhoudt et al., 2018). Traditionally, the motor learning process has been modelled sequentially, from a verbal-cognitive phase to the autonomous phase. This type of learning process, however, requires a qualified supervisor, teacher, or coach to prescribe "ideal" movement patterns and reduce any deviation from these. Alternative forms of learning, e.g. implicit learning, do not necessarily need a qualified supervisor but can be realised by creating environments that "guide" and "challenge" the child or athlete in such a way that the desirable outcome will be achieved. Underpinning the design of these environments is the aim to support learning as a process of discovering, exploring, and improving motor skills. Specifically, we introduce and outline the concentric approach to practice that aims to structure learning tasks and environments that allow the individual to solve their own motor problems. The freely emerging co-adaptation amongst individuals involved in the learning system enhances creativity and adaptability of the learners and coaches alike-the topic of Sections 3 and 4.

\section{A road to expertise: the athletic skills model}

The athletic skills model is based on the approach that body and mind form one unity, as a complex, adaptive system (Wormhoudt, Teunissen, \& Savelsbergh, 2012). The basics of this model is informed by the combination of theoretical ideas from ecological dynamics, key scientific findings, and experiential knowledge from extensive practice in (high performance) sport (Wormhoudt et al., 2018). The ASM programme introduces the following development framework:

- first, the child needs to become a versatile "good mover" that movement associates with fun ${ }^{1}$;

- subsequently, s/he will develop into an athlete;

- as an athlete the child will specialize in one sport, and;

- will finally develop into the absolute specialist within this sport.

So, the key of ASM is: first become an athlete, only then specialize as an athlete.

This sequence is not fixed by age, but more or less to skills required for the future aim, which can include becoming an elite or recreational athlete. The ASM programme seeks to create a stable basis for performance by developing a "physical" intelligence on which a healthy sporting career can be developed. The model builds on the other established models such as classic talent model of Bloom (1985), the diversification ideas of Côté et al. (1999, 2011, 2015), the different pedagogic aims of Balyi and Hamilton (2004), and the early engagement idea of Ford, Ward, Hodges and Williams (2009) (see table 2.4 page 46 in Wormhoudt et al., 2018). The ASM strives for fitter, adaptable, more rounded individuals who will establish a longer professional career as an athlete. As a consequence of more variation in the exercises, in comparison to monotonic programmes, the chances of getting injured are decreased significantly (methods are explained in 3 ). As a result they have more performance-related growth opportunities, which can enhance their personal development and general health and wellbeing. These aims fit very

\footnotetext{
${ }^{1}$ We developed a movement track that can measure the movement abilities of children and can be used in order to establish the level of fundamental movement abilities (Hoeboer et al., 2016, 2018).
} 
nicely into the description of physical literacy. Especially the first stage - to becomes a good mover (first an athlete) - which should enhance the physical literacy from early age onwards. The child is not "forced" into an early specialization trajectory but acquires all basic movement skills (e.g., fundamental movements) through movement education, for instance by doing a diversity of sports $^{2}$. We called this the multi- and donor sport program that can then be "hooked" into to any specific sport (see Sect. 5).

This key idea has clear evidence to support it. For example, Vaeyens et al. (2009) found a large varied sport participation, such as soccer, wrestling, field hockey, and figure skating, that top class athletes were engaged in when they were young (Horning, Aust, \& Gullich, 2016; Vaeyens, Gullich, Warr, \& Philippaerts, 2009). On the contrary, early sport specialization has been shown to lead to drop out. Barynina and Vaitsekhovskiis (1992) showed that top-class swimmers who specialized in swimming early in life spent less time with the national swimming team and stopped their career earlier than top-class swimmers who specialized in swimming at a later age (in Côté, Lidor, \& Hackfort, 2011).

Further support originates from a recent study by Gulbin, Weissensteiner, Oldenziel and Gagne (2013) in which developmental trajectories of elite athletes were analysed. These researchers examined the performance pathway trajectories and transitions experienced by 256 elite athletes across 27 different sports. One of the cornerstones of early specialization is the assumption of a linear trajectory from junior to elite. They, however, found that three main pathways, pure linear ascent, mixed ascent and mixed descent, account for 16.4, 26.2, 57.4\%, respectively. These pathways are further subdivided into eight sub-categories, which were a mix of linear, crossover, and concurrent profiles. In fact, Gulbin et al. (2013) report that only in $7 \%$ of cases a developmental linear pathway was observed for the transition from junior to senior. Thus, the majority of athletes followed a non-linear trajectory (mixed ascent and mixed descent) toward high levels of performance in a given sport. This implies that any model aiming to increase the physical literacy should take these non-linear developmental trajectories into account (including the possibility to follow the linear developmental pathway). In fact the linear development is just a special case of non-linear development. The ASM program is tailored to mixed developmental trajectories by applying a concentric developmental approach.

\section{Concentric developmental approach to basic movement skills}

What does a concentric development mean in the process of acquiring basic movement skills? It means that, for example, one basic movement skill like hitting a ball in

\footnotetext{
${ }^{2}$ Several researcher highlighted the relationship between good movement skills and sport participation (e.g. Barnett et al., 2016; Logan, Webster, Getchell, Pfeiffer, \& Robinson, 2015).
}

tennis, can be developed optimally by practising and experiencing all types of hitting as applied in other sports and activities. For instance, a versatile concentric approach to hitting in tennis is: hitting a baseball, playing table tennis, playing golf, Lacrosse, or performing a volleyball smash. In contrast, a linear development program is inherently limiting. In linear approaches, the next step is pre-set (based on some putative model) and is ultimately designed for only one purpose, to achieve a goal or execute an exercise, for example from rolling (rotating) to a somersault. These linear programs are mainly designed for the execution of a specific exercise (i.e., somersault) whereas a concentric program is designed for the intensification and development of human abilities or skills, which is much more in line with achieving a high level of physical literacy. Because the athlete can readily realise a diversity of actions across a range of contexts, it can also support a higher degree of adaptability and lead to unique and functional solutions (i.e., creativity) during game play (Santos, Memmert, Sampaio, \& Leite, 2016). In daily circumstances, rolling does not always (most of the time not) end in a somersault. It should be trained in depth and as a precursor to multiple relations: for transiting in horizontal, vertical and diagonal directions. For instance, rolling (rotating) is possible in three planes around multiple axes, such as when performing a pirouette in ballet, pivots in games like basketball, a judo throw, cartwheels, taekwondo spinning kicks, and a somersault in gymnastics. This transfer-ability is applicable to all basic movement skills. They all should be offered and integrated in a broad spectrum of complex skills and are in fact complex forms of neuromuscular training. The concentric developmental approach provides a variation in exercises that stimulate and challenge the creativity and adaptability of the child, athlete, and $\operatorname{coach}^{3}$.

\section{Setting limits: creativity, adaptability, and the constraint-led approach}

A theoretical motor learning model that is very useful to use when setting up a training session, is the constraints-led model by Newell (1986). The main idea of this model is that a produced coordinative movement pattern is the result of the interaction between the task, the environment in which this task has to be performed, and the movement possibilities of the organism (e.g., performer, athlete, or child) (Newell, 1986). These three categories of constraints together shape the limits of functional coordination patterns. When one of these three factors experiences a critical change, this becomes

\footnotetext{
${ }^{3}$ A concentric approach of basic movement skills means also a concentric approach of all coordinative abilities i.e. spatial awareness; rhythmic ability; kinaesthetic differentiation or synchronization of movement, and all conditions of movement i.e. agility; stability; flexibility or power (Wormhoudt et al., 2018).
} 
immediately visible in the coordinative movement pattern. In other words, by manipulation of any one category of constraint one can encourage certain movement patterns to emerge and also narrow or broaden the possible variation in the individuals' emergent patterns of coordination. The concentric approach can be used to manipulate task related factors for numerous sport environments. For example, the concentric approach to manipulating task constraints would aim to promote adaptability in throwing a ball across a diversity of contexts. The throwing off a wicket by a fielder at fifteen meters distance (promoting accuracy before speed) in cricket will be executed differently than a throw of an outfielder towards the home plate in baseball (mainly fast).

By designing how task, individual, and environmental constraints interact, situations can be created that support adaptability and creativity of the performer because they require a search for useful movement solutions that solve the motor problem at hand. When manipulating constraints, the coordination pattern is influenced without any instruction and, in some cases, this can lead to new and highly functional behaviour (Orth, van der Kamp, Memmert, \& Savelsbergh, 2017). In this respect, creative solution that results in adaptive actions can emerge without that necessarily being the aim of the individual - the learner is simply aiming to succeed at the task. In other words: by creating or setting limits you can expand your performance limit (Savelsbergh, Verheul, van der Kamp, \& Marple-Horvat, 2007).

Examples of constraints manipulation can be found in recent tennis studies. In a study of Timmermans et al., the influence of scaling court-size and net height on children's tennis performance is examined (Timmermans, De Water, Kachel, Reid, Farrow, \& Savelsbergh, 2015). Ten-year-old boys performed a 30-minutes match in four different conditions, where court-size and/or net height was scaled using a ratio based on the differences in temporal demands between the children and the adult game. The players hit more winners; more forced errors, played more volleys, struck more shots from a comfortable height and played in a more forward court position when the net is scaled. Scaling both the court and net led to a faster children's game, more closely approximating what is typical of the adult game. Importantly, children enjoyed playing on the standard court - scaled net condition more than standard adult conditions.

In a second tennis example, the immediate effect of lowering net height on the performance characteristics of skilled junior tennis players aged 10 years and younger were examined (Limpens, Buszard, Shoemaker, Savelsbergh, \& Reid, 2018). The net height in tennis (0.91 m) was set at approximately $50 \%$ of a professional tennis player's height. The findings show that lowering the net height to 0.65 and $0.52 \mathrm{~m}$ led to players adopting without prior instruction a more attacking style of play, as evidenced by a significant increase in the number of winners without a commensurate increase in errors and more shots struck inside the baseline. Lower nets also led to a greater percentage of successful first serves.
A third example stemming from a team sport, field hockey by Timmerman, Farrow and Savelsbergh (2017) in which the influence of manipulating game constraints on match performance in youth field hockey was studied. Participants aged 10-15 years old played four different 25 min games where density $\left(228 \mathrm{~m}^{2}\right.$ or $158 \mathrm{~m}^{2}$ per player) and/or number of players ( 11 per side or 8 per side) were manipulated. Manipulating the number of players led to an increase in a successful passes, skilled and successful actions performed per player and also created a more advantageous environment to enhance decision-making. Increasing the density led to a decrease in unsuccessful dribbles played by children and an increase in high intensity running and sprinting. The findings of this study provide an insight into the effect of manipulating task constraints in skilled junior field hockey and the findings highlight that all types of constraints influence emergent performance in their unique way and that teachers and coaches should consider these interactions to promote specific playing behaviour.

With this constraint-led perspective, the coach or teacher can mark and limit the environment in such a way that this guides the learning. For instance by scaling the equipment and play area a sub-conscious mode of learning will be encouraged (see for review: Buszard, Reid, Masters, $\&$ Farrow, 2016). Scaling the environment allows children to perform actions that resemble the adult game while maintaining the learning focus on what is fundamentally necessary for skilled performance-being adaptive during game play. Scaling constraints also increase the opportunity to discover (creativity) and learn (adapt) the technique relevant to the athlete's individual constraints. This is in contrast with providing verbal instructions, which direct an individual learner towards the execution of some presupposed movement. Further, the practitioner can stimulate movement stability by designing constraints where athletes can undertake repetition with variation during game play (e.g., by means of the concentric approach) - an eminently more enjoyable context for skills development than prescribed drills. This will help the athlete to come to solutions that work best for them and it will stimulate and support adaptability by exposing them to broader range of circumstances under which the same task goal needs to be met. More generally, fun and variation are elementary and beneficial for human health and well-being development (Wormhoudt et al., 2018). The ASM programme takes care of this key idea by introducing new forms of learning in addition to using well-known motor learning methods, which promote variation between sports, as well as within a specific sport. Within the ASM programme the various forms of learning, like implicit (Masters, 2000), analogy, errorless (Savelsbergh, Canal-Bruland, \& van der Kamp, 2012), differential learning (Schollhorn, 2005; Savelsbergh, Kamper, Rabius, de Koning, \& Schollhorn, 2010) are bridged by using a concentric approach. We will not elaborate here on these learning studies, but for the interested reader see chapter 4 in Wormhoudt et al. (2018) and Kleynen et al. (2015). 


\section{Roads to physical literacy and expertise from an ASM point of view}

In order to increase the level of physical literacy and thus increase the foundation for a road to expertise we need to take two important points into consideration. First, as Gulbin et al. (2013) report, only a minority of cases followed a developmental linear pathway, while the majority of athletes followed a non-linear trajectory. Thus, we should be able to accommodate both, linear and non-linear developmental trajectories. Second, we should be able to create learning environments that foster adaptability. In the process of solving motor problems, the performer can find movement solutions that lead to new and highly functional, creative behaviour (Orth, van der Kamp, Memmert, \& Savelsbergh, 2017). By encouraging greater diversification of capabilities in a population of learners and athletes, the greater the adaptability and creativity of the developmental system overall. Considering those points, we advocate three major roads to achieve higher levels of the physical literacy and expertise. These include:

- by using the concentric approach to movement skills acquisition (as explained in Sect. 2);

- by creating challenging environments from a constraints-led perspective (introduced in Sect. 4);

- by exploiting the transfer-ability of movements (discussed below).

In operationalizing these ideas, we have recently proposed the building of a completely new environment: The Skills Garden (road 2). The Skills Garden can be described as an attractive, innovative, and sustainable outdoor facility that can be used for leisure, playing, education, training, practice, and rehabilitation. All elements are modular and can be implemented on existing or new locations. This public facility, conforming to the ASM principles, enables an all-round motoric development by the use of all 10 basic movement skills as defined by Wormhoudt et al. (2018), such as balancing, climbing, throwing, catching, and jumping. This concept has been installed at the Football club AFC Ajax, Football Medical Centre at Zeist and at the KNVB, Dutch National Football Association Campus (see Fig. 1 for an outdoor and indoor facility). The Skills Garden stimulates, challenges and provides a pleasurable movement experience that stimulates adaptability (see for elaborative description Chapter 10 of Wormhoudt et al., 2018). It focuses on health, fitness, and sports and activities and can be used for leisure, playing, education, training, practice, and rehabilitation, and therefore contribute to the enhancement of the physical literacy.

With respect to road 3, ASM design principles exploit the transferability of movements. The concept of transfer of learning holds that previous practice or experience in one task or domain will enable (positive transfer) or inhibit (negative transfer) successful performance in another related task or domain (Côté, Baker, \& Abernethy, 2007).
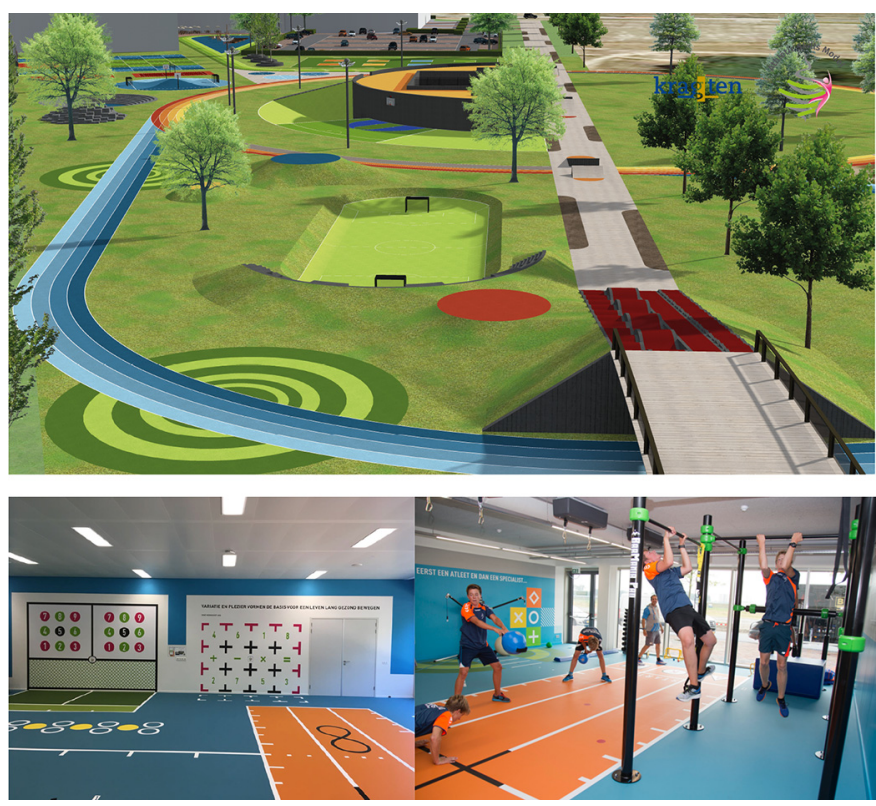

Fig. 1. Top image: The Skills Garden is important for health, fitness and sports. It's an attractive, innovative and sustainable outdoor facility for public space that can be used for leisure, playing, education, training, practice and rehabilitation. (Image by ASM and Kragten). Bottom Image: Indoor facility based on the same principles of ASM as the Skill Garden.

As stated earlier, the ability to adaptively and flexibly modify movement behaviour is a key component contributing to the varied repertoire of skilled actions. This is where the concept of multi- and donorsports comes into play. It is already well-known and suggested that practising multi-sports (multiple sport or also called sampling by Côté et al., 2007) is beneficial for health and social reasons but, also for developing better performance in a target sport. It may lead to numerous positive growth and developmental opportunities (Côté et al., 2011). For instance, it is well-known that international medallist have been engaged in more practice in other sports than their main sport during childhood and adolescence (Gullich, 2014, 2017; Horning et al., 2016)

However, similarities between sports are so often much greater than the differences. There is transfer of learning of the same basic movement skills, between different sports as well as within the same sport (Côté et al., 2007; Wolstencroft, 2002). From this point of view, we have to look for the similarities and differences in sports to see if the different sports or activities positively or negatively contribute to the performance of a target sport. To capture this idea, the ASM introduced the concepts of multi-sports and donorsports. Multi-sports refer to playing and sampling many other sports of which the basic movement skills of these sport are not or almost not present in your target (main) sport, but will enhance the level of physical literacy. Research shows that multi-sport is associated with reduced risk of injury (DiFiori et al., 2014; Myer et al., 2015) and drop out, that is, it prolongs engagement (Butcher, Lindner, \& Johns, 2002). Further by experienc- 
ing different sport, the probability that a sport is chosen in which one is talented, is increased (Gullich \& Emrich, 2014).

Donorsports refer to sports or activities that are selected to contribute to performance in the "chosen" target sport that consists of the same basic movement skills. This means that practising a donorsport will contribute to elements of the target sport and thus your expertise level in that particular sport (see for elaborate discussion Wormhoudt et al., 2018). Recent research supports this donorsport idea and shows a positive transfer for climbing from one environment to another one (Seifert, Wattebled, Orth, L'Hermette, Boulanger, \& Davids, 2016) and from futsal to football (Oppici, Panchuk, Serpiello, \& Farrow, 2018).

In the first example, the capability of climbers who had trained in indoor climbing to climb on outdoor icefalls for the first time was examined. Participants climbing fluency (performance) and number of exploratory actions (where the individual touches a hold with a hand or ice-axe only to withdraw it to find another or the same anchorage) were compared. It was found that the novice ice-climbers could successfully complete the ice route which- supported by a general transfer of skill between indoor and ice climbing. Specifically, the two conditions of climbing shared the need to counteract gravity on the vertically aligned surface and to use limb extremities to regulate bodyweight during vertical displacement. However, in the ice climbing task, the indoor climbers exhibited more exploratory actions and lower climbing fluency - suggesting that they used the basic skills of regulating bodyweight to help begin to learn skills specific to the ice climbing environment (such as determining if the icefall density was sufficient to support vertical ascent). While the emotional and psychological requirements for climbing icefalls would have been significantly different from those required to climb indoor walls, many of the underlying skills were similar (Seifert et al., 2016). In this case indoor climbing as a donorsport can help prepare individuals for safer exploration and more effective participation in ice climbing.

In a second example, it was investigated how learning a passing skill with futsal or association football task constraints influenced transfer to a new task. Fourteenyear-old players with either a background in futsal (the futsal group) or football (the football group) each performed two tasks. One task involved playing a smallsided game (5v5 + goalkeeper) - a futsal-like task (small playing area with the futsal ball). The second task was a football-like task (large playing area with the football). Players passing accuracy and their orientation of attention were assessed during the two tasks. The futsal group improved their passing accuracy from the futsal-like to the football-like task, and they were more accurate than football players. For the football group, passing accuracy remained stable across the two tasks and it was similar to the futsal group in the futsal-like task. These findings show a transfer (and adaptability) from performing passes in a small playing area with a short time to act - futsal task constraints - to a larger playing area with a longer time
- football task constraints - than vice-versa. Furthermore, the futsal group showed a higher adaptation of attention orientation to the affordances that emerged with the football task constraints. These results should encourage football practitioners to introduce futsal task constraints to fast-track players' ability to functionally adapt perception-action coupling (Savelsbergh \& van der Kamp, 2000). In other words, consider futsal as a donorsport for football.

Applying these three "ASM roads", the concentric approach, challenging environments, and exploiting transfer, each separately or in combination will increase the level of physical literacy as well as creativity and adaptability. In addition, all developmental pathways, linear as well as non-linear, can be served. For instance, for a child, the concentric approach and multi-sport can expand her/his potential for future development of performance into adulthood. For the recreational mover the concentric approach can be applied by doing multisports, or a concentric approach of a skill (e.g., balance) in the Skills Garden. For the elite athlete, donorsports carried out for instance in a Skills Garden will increase the level of expertise as a result of acquirement of wider network of perceptual-motor skills that "supports" the possibility of emergence of a greater diversity of movement solutions and problems they can be adapted to (Davids, Güllich, Araújo, \& Shuttleworth, 2017; Gullich, 2017). Finally, the current paper advocates that the ASM serves as a suitable model to structure (developmental) movement programs to enhance physical literacy with a view of supporting life-long physical activity participation and seeks to maintain a balance between performance, fitness, and health.

Acknowledgment. The authors are grateful to dr. Dominic Orth for very helpful comments on earlier drafts of this paper.

\section{References}

Anderson, G.S., \& Twist, P. (2005). Trainability of children. IDEA Fitness Journal, 1, 56-65.

Balyi, I., \& Hamilton, A. (2004). Long-term athlete development: Trainability in childhood and adolescence. Windows of opportunity. Optimal trainability. Victoria: National Coaching Institute British Columbia \& Advanced Training and Performance Ltd.

Barnett, L.M., Stodden, D., Cohen, K.E., Smith, J.J., Lubans, D., Lenoir, M., Iivonen, S., Miller, A., Laukkanen, A., Dudley, D., Lander, N.J., Brown, H., \& Morgan, F.J. (2016). Fundamental movement skills: An important Focus. Journal of Teaching in Physical Education, 35, 219-225.

Bloom, B.S. (1985). Developing talent in young people. New York: Ballantine Books.

Butcher, J., Lindner, K., \& Johns, D.P. (2002). Withdrawal from competitive youth sport: A retrospective ten-year study. Journal of Sport Behavior, 25, 241-163

Buszard, T., Reid, M., Masters, R.S.W., \& Farrow, D. (2016). Scaling the equipment and play area in children's sport to improve motor skill acquisition: A systematic review. Sports Medicine, 46, 829-843. 
Côté, J. (1999). The influence of the family in the development of talent in sport. The Sport Psychologist, 13, 395-417.

Côté, J., \& Erickson, K. (2015). Diversification and deliberate play during the sampling years. In Baker, J. \& Farrow, D. (Eds.), Routledge Handbook of Sport Expertise (pp. 305-316). London: Routledge.

Côté, J., Baker, J., \& Abernethy, B. (2007). Practice and play in the development of sport expertise. In G. Tenenbaum, R.C. Eklund (Eds.), Handbook of Sport Psychology (Vol. 3, pp. 184-202). Hoboken, NJ: John Wiley \& Sons, Inc.

Côté, J., Lidor, R., \& Hackfort, D. (2011). ISSP Position Stand: To sample or to specialize? Seven postulates about youth sport activities that lead to continued participation and elite performance. International Journal of Sport and Exercise Psychology, 7(1), 7-17.

Davids, K., Güllich, A., Araújo, D., \& Shuttleworth, R. (2017). Understanding environmental and task constraints on athlete development: Analysis of micro-structure of practice and macro-structure of development histories. In: J. Baker, S. Cobley, J. Schorer, \& N. Wattie (Eds.), Routledge Handbook of Talent Identification and Development in Sport. London: Routledge.

de Onis, M., Blossner, M., \& Borghi, E. (2010). Global prevalence and trends of overweight and obesity among preschool children. American Journal of Clinical Nutrition, 92(5): 1257-1264.

DiFiori, J.P., Benjamin, H.J., Brenner, J.S., Gregory, A., Jayanthi, N., Landry, G.L., \& Luke, A. (2014). Overuse injuries and burnout in youth sports: A position statement from the American Medical Society for Sports Medicine. British Journal of Sports Medicine, 48(4): 287-288.

Durden-Myers, E.J., Pot, N., \& Whitehead, M.E. (2018). Physical literacy and human flourishing. Journal of Teaching in Physical Education, 37, 308-311.

Ford, P.R., Ward, P., Hodges, N.J., \& Williams, M.A. (2009). The role of deliberate practice and play in career progression in sport: The early engagement hypothesis. High Ability Studies, 20(1), 65-75.

Gullich, A. (2014). Many roads lead to Rome-Developmental paths to Olympics gold in men's field hockey. European Journal of Sport Science, 14, 763-771.

Gullich, A. (2017). International medallists and non-medallists developmental sport activities-A match pairs analysis. Journal of Sport Sciences, 35, 2281-2288.

Gullich, A., \& Emrich, E. (2014). Considering long-term sustainability in the development of world class success. European Journal of Sport Science, 14, 383-397.

Gulbin, J., Weissensteiner, J., Oldenziel, K., \& Gagane, F. (2013). Patterns of performance development in elite athletes. European Journal of Sport Science, 13, 605-614.

Hill, R., McConnell, A., Forster, T., \& Moore, J. (2002). The path to excellence: A comprehensive view of development of U.S. Olympians who competed from 1984-1998. USOC, Performance Services Department, United States Olympic Committee, Colorado Springs CO.

Hoeboer, J., DeVries, S., Krijger-Hombergen, M., Wormdhoudt, R., Drent, A., Krabben, K., \& Savelsbergh, G.J.P. (2016). Validity of an athletic skills track among 6- to 12-year old children. Journal of Sport Sciences, 34, 2095-2105.

Hoeboer, J.J.A.A.M., Ongena, G., Krijger-Hombergen, M., Stolk, E., Savelsbergh, G.J.P., \& De Vries, S.I. (2018). The athletic skills track: Age- and gender-related normative values of a motor skills test for 4- to 12-year-old children. Journal of Science and Medicine in Sport. doi: 10.1016/j. jsams.2018.01.014.
Horning, M., Aust, F., \& Gullich, A. (2016). Practice and play in the development of German top-level professional football players. European Journal of Sport Science, 16, 96-105.

Kleynen, M., Braun, S.M., Rasquin, S.M.C., Bleijlevens, M.H. C., Lexis, M.A.S., Halfens, J., Wilson, M., Masters, R., \& Beurskens, A. (2015). Multidisciplinary views on applying explicit and implicit motor learning in practice: An international survey. PLoS ONE, 10(8), e0135522. doi: 10.1371/ journal.pone.0135522.

Limpens, V., Buszard, T., Shoemaker, E., Savelsbergh, G.J.P., \& Reid, M. (2018). Scaling cinstraints in junior tennis: The influence of net height on skilled players' match-play performance. Research Quarterly for Exercise and Sport, 89, $1-10$.

Logan, S.W., Webster, E.K., Getchell, N., Pfeiffer, K., \& Robinson, L.E. (2015). Relationship between fundamental motor skill compentence and physical activity during childhood and adolescence: A systematic review. Kinesiology Review, 4, 416-426.

Masters, R.S.E. (2000). Theoretical aspects of implicit learning in sport. International Journal of Sport Psychology, 31, 530541.

Myer, G.D., Jayanthis, N., DiFiori, J.P. Faigenbaum, A.D., Kiefer, A.W., Logerstedt, D., \& Micheli, L.J. (2015). Sport specialization part 1: Does early sport specialization increase negative outcomes and reduce the opportunity for success in young athletes? Sports Health, 7, 437-442

Newell, K. (1986). Constraints on the development of coordination. In: M. Wade \& H.T. Whiting (Eds.), Motor development in children: Aspects of coordination and control. Dordrecht, Netherlands: Martinus Nijhoff.

Oppici, L., Panchuk, D., Serpiello, F.R., \& Farrow, D. (2018). Futsal task constraints promote transfer of passing skill to soccer task constraints. European Journal of Sport Science, 18(7), 947-954.

Orth, D., van der Kamp, J., Memmert, D., \& Savelsbergh, G. (2017). Creative motor actions as emerging from movement variability. Frontiers in Psychology, 8, 1903.

Pot, N., Whitehead, M.E., \& Durden-Myers, E.J. (2018). Physical literacy from philosophy to practise. Journal of Teaching in Physical Education, 37, 246-251

Santos, S.D., Memmert, D., Sampaio, J., \& Leite, N. (2016). The spawns of creative behavior in team sports: A creativity developmental framework. Frontiers in Psychology, 7, 1282.

Savelsbergh, G.J.P., \& Van der Kamp, J. (2000). Information in learning to coordinate and control movements: Is there a need for specificity of practice? International Journal of Sport Psychology, 31, 476-484.

Savelsbergh, G.J., Verheul, M., van der Kamp, J., \& MarpleHorvat, D. (2007). The visuomotor control of movement acquisition. In: J. Liukkonen, Y.V. Auweele, B. Vereijken, D. Alfermann, et al. (Eds.), Psychology for Physical Educators. Champaign, IL: Human Kinetics.

Savelsbergh, G.J.P., Kamper, W., Rabius, J., de Koning, J., \& Schollhorn, W. (2010). New methods to learn to start in speed skating. A differencial learning approach. International Journal of Sport Psychology, 41, 415-427.

Savelsbergh, G.J., Canal-Bruland, R., \& van der Kamp, J. (2012). Error reduction during practice: A novel method for learning to kick free-kicks in soccer. International Journal of Sport Science and Coaching, 7, 47-56.

Seifert, L., Wattebled, L., Orth, D., L'Hermette, M., Boulanger, J., \& Davids, K. (2016). Skill transfer specificity shapes perception and action under varying environmental constraints. Human Movement Science, 48, 132-141. 
Schollhorn, W. (2005). Differenzielles Lernen und Lehren von Bewegungen-Durch veränderte Annahmen zu neuen Konsequenzen. In H. Gabler, U. Gohner, \& F. Schiebl (Eds.), Zur Vernetzung von Forschung und Lehre der Biomechanik, Sportmotorik und Trainingswissenschaft. Hamburg: Feldhas, Edition Czwalina.

Singh, A., Uijtdewilligen, L., Twisk, J.W., van Mechelen, W., \& Chinapaw, M.J. (2012). Physical activity and performance at school. Archives of Pediatrics $\&$ Adolescent Medicine, 1(166), 49-55.

Timmerman, E.A., Farrow, D., \& Savelsbergh, G.J.P. (2017). The effect of manipulating task constraints on game performance in youth field hockey. International Journal of Sport Science \& Coaching, 12, 588-594.

Timmermans, E., De Water, J., Kachel, K., Reid, M., Farrow, D., \& Savelsbergh, G.J.P. (2015). The effect of equipment scaling on children's sport performance: The case for tennis. Journal of Sport Sciences, 33: 1093-1100.

TNO Kwaliteit van Leven. (2008). Trendrapport Bewegen en Gezondheid 2008-2009. Leiden, Netherlands: TNO.

Tremblay, M.S., \& Willms, J.D. (2000). Secular trends in the body mass index of Canadian children. Canadian Medical Association Journal, 163(11), 1429-1433.

Vaeyens, R., Gullich, A., Warr, C.R., \& Philippaerts, R. (2009). Talent identification and promotion programmes of Olympic athletes. Journal of Sports Sciences, 27(13), 1367-1380.
Vandorpe, B., Vandendriessche, J. Lefevre, J., Pion, J., Vaeyens, R., Matthys, S., Philippaerts, R., \& Lenoir, M. (2011) The Korperkoordinations Test fur Kinder: reference values and suitability for 6-12-year-old children in Flanders. Scandinavian Journal of Medicine and Science in Sports, 21, 378-388.

Whitehead, M.E. (2001). The concept of physical literacy: throughout the life course. London: Routledge.

Whitehead, M.E. (2010). Physical literacy: throughout the life course. London: Routledge.

Whitehead, M.E., Durden-Myers, E.J., \& Pot, N. (2018). The value of fostering physical literacy. Journal of Teaching in Physical Education, 37, 252-261.

Wolstencroft, E. (2002). Talent Identification and Development. Edinburgh: SportScotland.

World Health Organization. (2009). Prevelance of overweight and obesity in children and adolescents. Geneva: WHO, European Environment Health Information System.

Wormhoudt, R., Teunissen, JW., \& Savelsbergh, G.J.P. (2012). Het athletic skills model voor een optimale talent ontwikkeling. (athletic skills model for optimizing talent development). London: Taylor Francis Group. Arko Sports Media.

Wormhoudt, R., Savelsbergh, G.J.P., Teunissen, JW., \& Davids, K.W. (2018). The athletic skills model for optimizing talent development through movement education. London: Routledge.

Cite this article as: Savelsbergh GJP \& Wormhoudt R (2018) Creating adaptive athletes: the athletic skills model for enhancing physical literacy as a foundation for expertise. Mov Sport Sci/Sci Mot, 102, 31-38 